\title{
The Efficacy of Ultrasonography-Guided Radiofrequency Ablation in Patients With Benign Thyroid Goiters With a History of Unilateral Lobectomy
}

\author{
Hyo-Jun Kim (i] $\cdot$ Ki-Nam Park (ㄷ) $\cdot$ Seung-Won Lee (i) \\ Department of Otorhinolaryngology-Head and Neck Surgery, Soonchunhyang University Bucheon Hospital, Soonchunhyang University \\ College of Medicine, Bucheon, Korea
}

In patients with nodular goiters that cause symptomatic or cosmetic problems, surgical or medical treatment is currently indicated [1-3]. However, complications such as incision scars or postoperative hypothyroidism can occur after thyroidectomy. Previous studies have shown that ultrasonography (USG)-guided radiofrequency ablation (RFA) under local anesthesia has a similar efficacy to that of surgery and can serve as an alternative treatment for benign nodular goiters [3-6]. However, few studies have investigated the usefulness of RFA in patients with nodular goiters who have previously undergone unilateral lobectomy. Therefore, the aim of this study was to evaluate the efficacy of USG-guided RFA in patients with benign thyroid goiters who had previously undergone unilateral lobectomy and to evaluate whether RFA affected thyroid function in these patients.

Patients presenting to the Department of Otorhinolaryngology-Head and Neck Surgery at Soonchunhyang University Bucheon Hospital between February 2013 and December 2018 were prospectively studied. In total, 160 consecutive RFA procedures were performed in patients with solid or predominantly solid benign thyroid nodules that were cosmetically problematic or symptomatic. Of these patients, 14 had a history of unilateral lobectomy. This study was approved by the Institutional Review Board of the Soonchunhyang University College of Medicine

\footnotetext{
- Received January 28, 2020

Revised March 4, 2020

Accepted March 4, 2020

- Corresponding author: Seung-Won Lee

Department of Otorhinolaryngology-Head and Neck Surgery,

Soonchunhyang University Bucheon Hospital, Soonchunhyang University

College of Medicine, 170 Jomaru-ro, Wonmi-gu, Bucheon 14584, Korea

Tel: +82-32-621-5448, Fax +82-32-621-5016

E-mail:1sw0922@schmc.ac.kr
}

(IRB No. SCHBC_IRB_2011-21). All patients provided written informed consent.

The exclusion criteria were as follows: (1) patients with a nodule measuring $<10 \mathrm{~mm}$, (2) follicular neoplasm or malignancy on fine-needle aspiration (FNA), (3) USG findings suspicious for malignancy, and (4) previous radiotherapy or sclerosing therapy. USG examinations, FNA findings, thyroid function, and clinical concerns were evaluated before RFA. All patients underwent two USG-guided FNA biopsies to confirm whether the nodule was malignant and whether occult metastasis was present prior to the procedure. USG and USG-guided FNA were performed using a 12L-RS linear probe fitted to an ultrasound scanner system (LOGIQ P9, GE Healthcare, Seoul, Korea). The nodule volume was calculated as length width $\times$ height $\times \pi / 6$ (or $\times 0.52$ ).

To score the symptoms caused by the nodular goiters, patients were asked to rate their symptoms on a $10-\mathrm{cm}$ visual analog scale, ranging from 1 (no symptoms) to 4 (most severe symptoms). Physicians recorded a cosmetic score (1, no palpable mass; 2 , no cosmetic problem, but a palpable mass; 3 , a cosmetic problem on swallowing only; and 4 , a readily detected cosmetic problem) [7]. A single surgeon (SWL) performed RFA using an radiofrequency generator (VIVA RF generator; STARmed, Goyang, Korea) and an 18-gauge, 5 -mm or 7-mm tip internally cooled electrode (Well-point RF Electrode, STARmed). The tip was inserted into the nodule under USG guidance. All nodules were treated using the transisthmic approach and the movingshot technique [3,6]. After RFA, patients were admitted to check for postoperative complications; if they did not experience any complications, they were discharged the following day.

Statistical analyses were performed using SPSS ver. 18.0 (SPSS Inc., Chicago, IL, USA). Variables were compared using

Copyright () 2020 by Korean Society of Otorhinolaryngology-Head and Neck Surgery.

This is an open-access article distributed under the terms of the Creative Commons Attribution Non-Commercial License (https://creativecommons.org/licenses/by-nc/4.0) which permits unrestricted non-commercial use, distribution, and reproduction in any medium, provided the original work is properly cited. 
Table 1. Clinical data obtained at the first visit and at the 6- and 12-month follow-ups

\begin{tabular}{lccccc}
\hline Characteristics & First visit & 6-Month follow-up & $P$-value & 12-Month follow-up & $P$-value \\
\hline Diameter $(\mathrm{cm})$ & $3.07 \pm 0.86$ & $1.31 \pm 0.49$ & $<0.001$ & $0.96 \pm 0.58$ & $<0.001$ \\
Volume $(\mathrm{mL})$ & $4.49 \pm 0.99$ & $1.05 \pm 0.60$ & $<0.001$ & $0.63 \pm 0.55$ & $<0.001$ \\
Symptom score ${ }^{\text {a) }}$ & $1.29 \pm 0.61$ & $1.14 \pm 0.36$ & 0.157 & $1.07 \pm 0.26$ & 0.180 \\
Cosmetic score $^{\text {b) }}$ & $3.14 \pm 0.95$ & $1.14 \pm 0.36$ & $<0.001$ & $1.14 \pm 0.36$ & $<0.001$ \\
\hline
\end{tabular}

Values are presented as mean \pm standard deviation.

a)Patients were asked to rate their symptoms on a 10-cm visual analog scale, ranging from 1 (no symptoms) to 4 (most severe symptoms). b)Patients expressed their cosmetic problems on a 4-point scale (1, no palpable mass; 2 , no cosmetic problem, but a palpable mass; 3 , a cosmetic problem on swal-

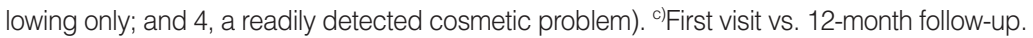

Table 2. Thyroid function tests performed at the first visit and at 6- and 12-month follow-ups for the seven patients who did not take Synthyroid before and after RFA

\begin{tabular}{lccccc}
\hline Characteristics & First visit & 6-Month follow-up & $P$-value & 12-Month follow-up & $P$-value ${ }^{\text {a) }}$ \\
\hline $\mathrm{T}_{3}(\mathrm{ng} / \mathrm{dL})$ & $1.11 \pm 0.22$ & $1.26 \pm 0.42$ & 0.175 & $1.13 \pm 0.35$ & 0.123 \\
Free $\mathrm{T}_{4}(\mathrm{ng} / \mathrm{dL})$ & $1.15 \pm 0.21$ & $1.08 \pm 0.06$ & 0.168 & $1.13 \pm 0.11$ & 0.173 \\
$\mathrm{TSH}(\mu \mathrm{l} / \mathrm{mL})$ & $2.91 \pm 0.21$ & $3.15 \pm 0.61$ & 0.265 & $3.13 \pm 0.41$ & 0.285 \\
\hline
\end{tabular}

Values are presented as mean \pm standard deviation.

RFA, radiofrequency ablation; $T_{3}$, triiodothyronine; $T_{4}$, thyroxine; $T S H$, thyroid-stimulating hormone.

a) First visit vs. 12-month follow-up.

the Wilcoxon sign-rank test at the time of the first visit and at the follow-up visit. The significance level was defined as $P<0.05$. Demographic data such as age, procedure time, and components of the nodule did not differ significantly according to whether patients had undergone unilateral lobectomy $(P>0.05)$. The mean cosmetic score decreased from $3.14 \pm 0.95$ at the first visit to $1.14 \pm 0.36$ at the 6-month follow-up and $1.14 \pm 0.36$ at the 12-month follow-up $(P<0.001)$. However, the symptom score did not change significantly at the 6- and 12-month follow-ups $(P>0.05)$ (Table 1).

At the first visit, the mean nodule volume was $4.49 \pm 0.99 \mathrm{~mL}$. After RFA, the mean nodule volume decreased significantly to $1.05 \pm 0.6 \mathrm{~mL}$ at the 6-month follow-up and $0.63 \pm 0.55 \mathrm{~mL}$ at the 12-month follow-up $(P<0.001)$ (Table 1$)$. The mean percentage of volume reduction demonstrated a similar trend, increasing from $79.4 \% \pm 17.6 \%$ at the 6 -month follow-up to $81.2 \% \pm 10.5 \%$ at the 12-month follow-up $(P<0.001)$. Thyroid function was assessed by measuring triiodothyronine $\left(\mathrm{T}_{3}\right)$, free thyroxine $\left(\mathrm{T}_{4}\right)$, and thyroid-stimulating hormone (TSH) levels, none of which significantly changed after RFA $(P>0.05)$ (Table 2$)$. No major complications such as permanent vocal cord paralysis, dyspnea, major vessel injury, esophagus injury, or thyrotoxicosis were observed during the follow-up period. In accordance with other studies demonstrating that the rate of recurrence was low, no regrowth of treated nodules in this study was observed $[2,4,8]$.

In the present study, RFA was found to be an effective and safe treatment, considering that the nodule volume was reduced by $>50 \%$ and cosmetic improvements were achieved without major complications. However, RFA did not lead to statistically significant improvements in symptoms. As there were some patients in our study with huge thyroid goiters that were large enough to compress surrounding structures, resulting in a variety of symptoms, the improvements in symptom scores in the patients in our study were not statistically significant. Unlike other studies, thyroid function tests including measurements of $\mathrm{T}_{3}$, free $\mathrm{T}_{4}$, and TSH levels were undertaken before and after RFA to determine whether RFA affected thyroid function in patients with nodular goiters who had previously undergone unilateral thyroidectomy. Seven patients in our study who did not receive $\mathrm{T}_{4}$ supplementation therapy before RFA maintained their thyroid function without the need for additional $\mathrm{T}_{4}$ supplementation after RFA. The other seven patients who took $\mathrm{T}_{4}$ supplements before RFA showed stable thyroid function, without an increase in the therapeutic dose after the procedure. These findings indicate that RFA did not cause thyroid function to deteriorate in patients who had undergone unilateral lobectomy.

Generally, open surgery for patients with only one functioning thyroid gland poses an elevated risk of recurrent laryngeal nerve injury and hypoparathyroidism, as well as inevitable permanent hypothyroidism resulting from the procedure $[5,6,9]$. Therefore, after the surgical procedure, patients must take medications for the rest of their life to control their thyroid function. According to the results of our study, for patients with nodular goiters who had previously undergone unilateral thyroidectomy, RFA - as opposed to open surgery - could lower the risk of these complications and the need for lifelong medications, without influencing thyroid function. In conclusion, RFA resulted in significant volume reduction without any serious complications or alteration of thyroid function, meaning that it can be used to treat benign solid nodular goiters that cause cosmetic or symptomatic problems in patients who have undergone unilateral lobectomy. 


\section{CONFLICT OF INTEREST}

No potential conflict of interest relevant to this article was reported.

\section{ACKNOWLEDGMENTS}

This research was supported by the National Research Foundation of Korea (NRF) funded by the Ministry of Science, ICT \& Future Planning, South Korea (grant no. 2017R1D 1A 1B 03029820) and the Soonchunhyang University Research Fund.

\section{ORCID}

$\begin{array}{ll}\text { Hyo-Jun Kim } & \text { https://orcid.org/0000-0002-3921-110X } \\ \text { Ki-Nam Park } & \text { https://orcid.org/0000-0001-6641-3981 } \\ \text { Seung-Won Lee } & \text { https://orcid.org/0000-0002-0468-8143 }\end{array}$

\section{AUTHOR CONTRIBUTIONS}

Conceptualization: SWL. Data curation: all authors. Formal analysis, Funding acquisition, Methodology, Project administration, \& Visualization: SWL. Writing-original draft: HJK. Writing-review \& editing: KNP, SWL.

\section{REFERENCES}

1. Knobel M. Which is the ideal treatment for benign diffuse and multinodular non-toxic goiters? Front Endocrinol (Lausanne). 2016 May; 23(7):48.

2. Che Y, Jin S, Shi C, Wang L, Zhang X, LiY, et al.Treatment of benign thyroid nodules: comparison of surgery with radiofrequency ablation. AJNR Am J Neuroradiol. 2015 Jul;36(7):1321-5.

3. Ha EJ, Baek JH, Lee JH, Sung JY, Lee D, Kim JK, et al. Radiofrequency ablation of benign thyroid nodules does not affect thyroid function in patients with previous lobectomy. Thyroid. 2013 Mar;23(3): 289-93.

4. Chung SR, Suh CH, Baek JH, Park HS, Choi YJ, Lee JH. Safety of radiofrequency ablation of benign thyroid nodules and recurrent thyroid cancers: a systematic review and meta-analysis. Int J Hyperthermia. 2017 Dec;33(8):920-30.

5. Baek JH, Kim YS, Lee D, Huh JY, Lee JH. Benign predominantly solid thyroid nodules: prospective study of efficacy of sonographically guided radiofrequency ablation versus control condition. AJR Am J Roentgenol. 2010 Apr;194(4):1137-42.

6. Na DG, Lee JH, Jung SL, Kim JH, Sung JY, Shin JH, et al. Radiofrequency ablation of benign thyroid nodules and recurrent thyroid cancers: consensus statement and recommendations. Korean J Radiol. 2012 Mar-Apr;13(2):117-25.

7. Baek JH, Lee JH, Valcavi R, Pacella CM, Rhim H, Na DG. Thermal ablation for benign thyroid nodules: radiofrequency and laser. Korean J Radiol. 2011 Sep-Oct;12(5):525-40.

8. Kim JH, Baek JH, Lim HK, Ahn HS, Baek SM, Choi YJ, et al. 2017 Thyroid Radiofrequency Ablation Guideline: Korean Society of Thyroid Radiology. Korean J Radiol. 2018 Jul-Aug;19(4):632-655.

9. Ugurlu MU, Uprak K, Akpinar IN, Attaallah W, Yegen C, Gulluoglu BM. Radiofrequency ablation of benign symptomatic thyroid nodules: prospective safety and efficacy study. World J Surg. 2015 Apr; 39(4):961-8. 